\title{
Genetic diversity for esterases in the recently evolved stabilized introgressant, Senecio vulgaris L. var. hibernicus Syme, and its parental taxa $S$. vulgaris L. var. vulgaris $L$. and S. squalidus $L$.
}

\author{
RICHARD J. ABBOTT, JUDITH A. IRWIN \& PAUL A. ASHTON \\ Department of Biology and Preclinical Medicine, Sir Harold Mitchell Building, University of St Andrews, St Andrews, \\ Fife KY16 9TH, UK
}

\begin{abstract}
The level of genetic diversity in the recently evolved stabilized introgressant Senecio vulgaris var. hibernicus was compared to that within its parental taxa, $S$. vulgaris var. vulgaris and $S$. squalidus, over three esterase loci $-\alpha E s t-1, \beta E s t-1$ and $\beta E s t-3$. It was established that var. hibernicus contained much less genetic diversity at the $\alpha E s t-1$ and $\beta E s t-3$ loci than was present in var. vulgaris. This was evident irrespective of whether var. vulgaris was sampled from populations containing both var. hibernicus and var. vulgaris or populations monomorphic for var. vulgaris. Moreover, the $\beta E$ st-1 locus which was present in $S$. squalidus, but absent from var. vulgaris, was also absent from var. hibernicus, while the $\beta E s t-3 b$ allele which occurred at high frequency (92 per cent) in $S$. squalidus was present at a low frequency ( 8 per cent) in var. hibernicus. It is concluded that var. hibernicus has gained no increased genetic diversity for esterases via introgression of germplasm from $S$. squalidus. The maintenance of a low level of genetic diversity for esterases in var. hibernicus, relative to var. vulgaris in populations containing both variants, was surprising in view of the level of intervariant crossing known to occur in such populations. The possibility of a post-mating breeding barrier existing between the two variants of $S$. vulgaris which might maintain genetic differences is briefly discussed.
\end{abstract}

Keywords: esterase diversity, introgression, population genetic structure, Senecio squalidus, Senecio vulgaris.

\section{Introduction}

Introgressive hybridization has long been recognized as a powerful mechanism for generating new genetic variation within plant species (Anderson, 1949, 1953; Stebbins, 1969; Grant, 1981). Only recently, however, has it been confirmed that certain products of the process may evolve into new variant forms of a species with distributions beyond the zone of active hybridization (Rieseberg et al., 1990; Abbott et al., 1992). In the genus Senecio, a survey of allozyme variation for aspartate aminotransferase (AAT) confirmed that the radiate variant of $S$. vulgaris L., var. hibernicus Syme, originated in Britain following introgression of germplasm from the introduced $S$. squalidus $(2 n=20)$ into the native non-radiate variant of $S$. vulgaris L., var. vulgaris L. $(2 n=40)$, (Abbott et al., 1992). The radiate variant, which produces capitula with ray florets, in contrast to the non-radiate variant with capitula containing only disc florets, is believed to have originated during the early part of the 19th century (Abbott et al., 1992), following the escape of $S$. squalidus from the Oxford Botanic Garden at the end of the 18th century (Druce, 1927). The variant is now widespread in Britain and occurs with the non-radiate variant as an early colonist of open disturbed ground in urban areas.

The survey of AAT variation conducted by Abbott et al. (1992) established that at one locus, Aat-3, which is duplicated in $S$. vulgaris, an allele which occurs at high frequency in British populations of $S$. squalidus was also common in radiate $S$. vulgaris var. hibernicus, but was rare among individuals of non-radiate $S$. vulgaris var. vulgaris which co-occurred with var. hibernicus and was absent from populations monomorphic for var. vulgaris. Apart from providing confirmation of the introgressive origin of var. hibernicus, the survey 
established that var. hibernicus exhibited greater genetic diversity than var. vulgaris for Aat-3.

Assuming a single or limited number of origins, a recently evolved stabilized introgressant is expected to contain only a sample of the allelic diversity present within the ancestral non-introgressed taxon. In addition, only a small proportion of genes specific to or at high frequency in the donor species is likely to become incorporated into a stabilized introgressant. Selection is expected to remove those donor genes which reduce fitness, while repeated backcrossing to the 'recipient' species will reduce the frequency of donor genes which are selectively neutral. Founder effects and drift may act to oppose the loss of donor alleles (especially in a colonizing species such as $S$. vulgaris), as will mating which reduces backcrossing, e.g. positive assortative mating and/or self-fertilization. Eventually, however, those donor alleles which remain present in a stabilized introgressant are likely to have been favoured by selection or associated with loci at which such alleles occur.

To provide an estimate of genetic diversity in $S$. vulgaris var. hibernicus, relative to that within var. vulgaris and $S$. squalidus at loci other than the Aat-3 locus, a survey of allozyme variation was conducted over 12 additional enzyme systems. Of these systems, only two $(\alpha$ - and $\beta$-esterase) proved to be polymorphic in British $S$. vulgaris. This paper, therefore, centres on the results of a survey of esterase variation in the three taxa of Senecio following a genetic analysis of the inheritance of esterase variants in $S$. vulgaris.

\section{Materials and methods}

Seeds or whole plants of $S$. vulgaris var. hibernicus and var. vulgaris were collected from 18 British populations that were polymorphic for capitulum type. In addition, seeds were collected from seven populations monomorphic for var. vulgaris, and from 23 British populations of $S$. squalidus. Site descriptions are given in Ashton (1990) and Irwin (1990). The seed of each parent plant sampled was germinated to provide one offspring per mother plant for electrophoresis. Alternatively, material from individuals collected directly from the field was used for electrophoresis.

Starch gel electrophoresis was conducted on crude protein extracts of young leaves or flower buds. The following enzymes were assayed: acid phosphatase, $\alpha$-esterase $(\alpha \mathrm{EST}), \quad \beta$-esterase ( $\beta \mathrm{EST})$, glucose-6phosphate dehydrogenase, glutamate dehydrogenase, glyceraldehyde-3-phosphate dehydrogenase, malate dehydrogenase, malic enzyme, peroxidase, 6-phosphogluconate dehydrogenase, phosphoglucomutase, and phosphoglucose isomerase. Details of electrophoretic and staining procedure are given in Ashton
(1990) and Irwin (1990). British material of S. vulgaris (var. vulgaris and var. hibernicus) was found to be monomorphic for all systems assayed except $\alpha$ - and $\beta$-esterase.

\section{Genetic analysis of esterase variants}

A preliminary survey of esterase variation in a sample of $S$. vulgaris from Edinburgh (Nat. Grid Ref. NT261762) revealed polymorphism within one zone of activity on gels stained for $\alpha$-esterase, and in two zones of activity on gels stained for $\beta$-esterase (Fig. 1). Two esterase bands, fast and slow, occurred in both the $\alpha E s t-1$ and $\beta E s t-2$ zones of activity, while three bands - fast, intermediate and slow - were resolved in the $\beta E s t-3$ zone of activity. The most anodally migrating (fast) isozyme within each zone was designated $a$, the next $b$, and so on. The esterase variation found in the Edinburgh sample encompassed the range of variants detected subsequently in other populations of $S$. vulgaris. Crosses were made between true breeding individuals which exhibited different single banded phenotypes in one or more zones of esterase activity (Table 1). Details of the crossing procedure are given in Irwin (1990) and Abbott et al. (1992). $F_{1}$ offspring, and $F_{2}$ families (produced after selfing $F_{1}$ ), were grown on and screened for esterase phenotype. In cases where parents were of alternative capitulum type, plants were raised to flowering and recorded for capitulum type.

In $S$. squalidus, a preliminary survey of material sampled from Edinburgh (Nat. Grid Ref. NT268765) revealed the same esterase variants within the $\beta E s t-2$ and $\beta E s t-3$ zones of activity as found in $S$. vulgaris. It was assumed that the inheritance of variants within the $\beta E s t-3$ zone was the same as in $S$. vulgaris (see below). $S$. squalidus, in contrast to $S$. vulgaris, did not exhibit any $\alpha$-esterase activity, but produced a third zone of $\beta$-esterase activity $(\beta E s t-1)$ with individuals showing monomorphism for a single band $(\beta E s t-1 a)$. Lack of expression of $\beta E s t-1$ in $S$. vulgaris and $\alpha E s t-1$ in $S$. squalidus seems to result from gene absence rather than suppression, as both genes are expressed in the allohexaploid $S$. cambrensis which combines the genomes of both species (Ashton \& Abbott, 1992; and personal observation).

\section{Results}

\section{Inheritance of esterase variation in $\mathrm{S}$. vulgaris}

For $\alpha E s t-1$ and $\beta E s t-3$, crosses between parents which differed in single-banded phenotype produced $F_{1}$ offspring exhibiting a double-banded phenotype. The $\mathrm{F}_{2}$ families segregation fast-, double- and slow-banded 
phenotypes in a ratio not significantly different from 1:2:1 (Table 1). It is concluded that variation for each of these enzymes is controlled by a single locus with two co-dominant alleles occurring at the $\alpha E s t-1$ locus, and three co-dominant alleles at the $\beta E s t-3$ locus.

For $\beta E s t-2, F_{1}$ offspring produced a single fastbanded phenotype $(\beta E s t-2 a)$, while in the $F_{2}$, fast and slow $(\beta E s t-2 b)$ banded phenotypes segregated in a ratio not significantly different from $3: 1$. A possible explanation for the absence of the expected double banded 'heterozygous' phenotype in the $F_{1}$ and $F_{2}$ generations, is that variation for $\beta E s t-2$ is due to polymorphism at a 'modifier' locus which has an effect on the electrophoretic properties of the esterase produced by the $\beta E s t-2$ locus. The occurrence of modifier genes which affect the mobility of particular proteins in plants and animals is well known (Manwell \& Baker, 1970; Weeden \& Wendel, 1989), and can cause one electrophoretic variant to appear to be dominant to another. In the two crosses which involved parents with alternative capitulum types, the $F_{2}$ plant's segregated radiate, intermediate and non-radiate phenotypes in a ratio not significantly different from 1:2:1 (Table 1). This confirmed the disomic monogenic inheritance of capi- tulum type in $S$. vulgaris previously reported by Trow (1912), Hull (1974) and Abbott et al. (1992).

Chi-squared contingency tests of the joint segregation of pairs of loci revealed no evidence of linkage between the locus controlling capitulum type (ray floret locus) and the three esterase loci ( $\alpha E s t-1, \beta E s t-2$ and $\beta E s t-3)$ (Table 2). There was also no evidence of linkage between the $\beta E s t-2$ locus (or the modifier locus which may produce polymorphism for $\beta E s t-2$ ) and the two other esterase loci. Only between the $\alpha E s t-1$ and $\beta E s t-3$ loci was linkage established. The recombination fraction between this pair of loci was calculated for each of four different crosses using the maximum likelihood procedures of Allard (1956). This was conducted by means of the LINKAGE-1 program of Suiter et al. (1983). For three of the crosses the recombination fraction ranged between 0.32 and 0.38 , however in the fourth cross the value dropped to 0.22 .

\section{Genetic diversity}

In view of the inability to resolve a 'heterozygous' double-banded phenotype at the $\beta E s t-2$ locus, and also because $\beta E s t-2$ frequently showed weak activity

Table $1 \chi^{2}$ tests for segregation ratio of phenotypes for capitulum type and $\alpha E s t-1$ $\beta E s t-2$ and $\beta E s t-3$ type in the $F_{2}$ families of crosses between different lines of $S$. vulgaris. Enclosed in brackets are the designated genotypes of parents at the $\alpha E s t-1, \beta E s t-2$ and $\beta E s t-3$ loci respectively

\begin{tabular}{lcccc}
\hline Parents & \multicolumn{2}{c}{$F_{2}$ phenotype } & $\chi^{2}$ \\
\hline (a) Capitulum type & $R R$ & $R N$ & $N N$ & \\
E37-RR $(a a, a a, c c) \times \mathrm{E} 45-N N(b b, b b, c c)$ & 16 & 43 & 19 & 1.05 \\
E40-RR $(a a, b b, c c) \times \mathrm{E} 49-N N(b b, b b, a a)$ & 16 & 42 & 18 & 0.95 \\
(b) $\alpha E s t-1$ type & $a a$ & $a b$ & $b b$ & \\
E37-RR $(a a, a a, c c) \times \mathrm{E} 45-N N(b b, b b, c c)$ & 22 & 50 & 25 & 0.36 \\
E40-RR $(a a, b b, c c) \times \mathrm{E} 49-N N(b b, b b, a a)$ & 21 & 48 & 27 & 0.75 \\
E22-NN $(a a, a a, c c) \times \mathrm{E} 49-N N(b b, b b, a a)$ & 49 & 73 & 47 & 3.18 \\
E45-NN $(b b, b b, c c) \times \mathrm{E} 46-N R(a a, b b, b b)$ & 21 & 43 & 31 & 2.96 \\
E49-NN $(b b, b b, b b) \times \mathrm{E} 46-N R(a a, b b, b b)$ & 31 & 54 & 19 & 2.92 \\
(c) $\beta E s t-2$ type & $a$ & & $b b$ & \\
E37-RR $(a a, a a, c c) \times \mathrm{E} 45-N N(b b, b b, c c)$ & 66 & & 31 & 2.47 \\
E22-NN $(a a, a a, c c) \times \mathrm{E} 49-N N(b b, b b, a a)$ & 128 & & 41 & 0.05 \\
E46- $N R(a a, b b, b b) \times \mathrm{E} 31-N N(a a, a a, c c)$ & 72 & & 28 & 0.48 \\
E22-NN $(a a, a a, c c) \times \mathrm{E} 4-N N(a a, b b, a a)$ & 79 & & 21 & 0.85 \\
(d) $\beta E s t-3$ type & $a$ & $a c$ & $c c$ & \\
E22-NN $(a a, a a, c c) \times \mathrm{E} 49-N N(b b, b b, a a)$ & 45 & 90 & 34 & 1.43 \\
E22-NN $(a a, a a, c c) \times \mathrm{E} 4-N N(a a, b b, a a)$ & 16 & 60 & 24 & 5.28 \\
E40-RR $(a a, b b, c c) \times \mathrm{E} 49-N N(b b, b b, a a)$ & 28 & 44 & 24 & 1.00 \\
E46-NR $(a a, b b, b b) \times \mathrm{E} 31-N N(a a, a a, c c)$ & 17 & 58 & 25 & 3.84 \\
E45-NN $(b b, b b, c c) \times \mathrm{E} 46-N R(a a, b b, b b)$ & 22 & 46 & 27 & 0.62 \\
E49-NN $(b b, b b, a a) \times \mathrm{E} 46-N R(a a, b b, b b)$ & 25 & 59 & 20 & 2.36 \\
\hline
\end{tabular}


Table 2 Results of $\chi^{2}$ contingency tests for joint segregation of alleles at the ray floret and esterase loci

\begin{tabular}{llll}
\hline Parents & d.f. & $\chi^{2}$ & $r \pm-$ S.E. \\
\hline (i) Ray floret: $a E s t-1$ & & & \\
E37-RR $(a a, a a, c c) \times \mathrm{E} 45-N N(b b, b b, c c)$ & 4 & 5.26 & \\
E40-RR $(a a, b b, c c) \times \mathrm{E} 49-N N(b b, b b, a a)$ & 4 & 3.48 & \\
(ii) Ray floret: $\beta E s t-2$ & & & \\
E37-RR $(a a, a a, c c) \times \mathrm{E} 45-N N(b b, b b, c c)$ & 2 & 0.50 & \\
(iii) Ray floret: $\beta E s t-3$ & & & \\
E40-RR $(a a, b b, c c) \times \mathrm{E} 49-N N(b b, b b, a a)$ & 4 & 4.65 & \\
(iv) $\alpha E s t-1: \beta E s t-2$ & & & \\
E37-RR $(a a, a a, c c) \times \mathrm{E} 45-N N(b b, b b, c c)$ & 2 & 1.79 & \\
E22-NN $(a a, a a, c c) \times \mathrm{E} 49-N N(b b, b b, a a)$ & 2 & 0.37 & \\
(v) $\alpha E s t-1: \beta E s t-3$ & & & \\
E40-RR $(a a, b b, c c) \times \mathrm{E} 49-N N(b b, b b, a a)$ & 4 & 15.29 & $0.32 \pm 0.04$ \\
E22-NN $(a a, a a, c c) \times \mathrm{E} 49-N N(b b, b b, a a)$ & 4 & 21.11 & $0.35 \pm 0.03$ \\
E45-NN $(b b, b b, c c) \times \mathrm{E} 46-N R(a a, b b, b b)$ & 4 & 44.28 & $0.22 \pm 0.03$ \\
E49-NN $(b b, b b, b b) \times \mathrm{E} 46-N R(a a, b b, b b)$ & 4 & 6.98 & $0.38 \pm 0.04$ \\
(vi) $\beta E s t-2: \beta E s t-3$ & & & \\
E22-NN $(a a, a a, c c) \times \mathrm{E} 49-N N(b b, b b, a a)$ & 2 & 1.79 & \\
E22-NN $(a a, a a, c c) \times \mathrm{E} 4-N N(a a, b b, a a)$ & 2 & 3.15 & \\
E46- $N R(a a, b b, b b) \times \mathrm{E} 31-N N(a a, a a, c c)$ & 2 & 1.70 & \\
\hline
\end{tabular}

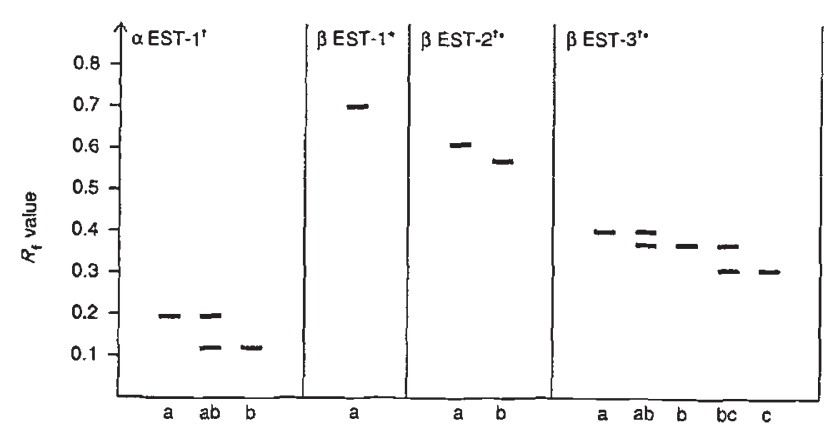

Fig. 1 Electrophoretic phenotypes resolved for esterases in Senecio vulgaris $\dagger$ and $S$. squalidus*. (The $\beta E s t-3 b, b c$ and $c$ phenotypes correspond to the $\beta E s t-3 a, a b$ and $b$ phenotypes in Ashton \& Abbott, 1992).

making identification of the phenotype difficult in some samples, the survey of esterase diversity was restricted to the $\beta E s t-3$ locus in $S$. squalidus and the $\alpha E s t-1$ and $\beta E s t-3$ loci in $S$. vulgaris. The most common allele at the $\beta E s t-3$ locus in all populations. of $S$. squalidus was the $\beta E s t-3 b$ allele (Table 3 ). This allele was fixed in five out of 23 populations surveyed, and occurred at a frequency of 92 per cent over all individuals examined. It follows that the total gene diversity $\left(H_{T}\right)$ estimated according to $\mathrm{Nei}(1973)$, i.e.

$H_{T}=1-\sum_{i=1}^{\kappa} \tilde{x}_{i}^{2}$ where $\bar{x}_{i}^{2}$ is the mean frequency of the $i$ th of $K$ alleles for the populations surveyed, was low in $S$. squalidus at the $\beta E$ st -3 locus (Table 4 ), and resulted largely from diversity within populations $\left(H_{S}\right)$ rather than between them $\left(D_{S T}\right) . F$ statistics (Wright, 1951) computed using the computer package BIOsYS-1 (Swofford \& Selander, 1981), showed that the overall correlation between uniting gametes $\left\langle F_{I T}\right)$ was greater than expected with panmixia, due largely to a deficiency in heterozygotes from expected within populations $\left(F_{I S}\right)$ rather than genetic subdivision between populations $\left(F_{S T}\right)$ (Table $5)$. Nevertheless, positive fixation index values $\left(F_{0}\right)$ were computed for only half of the 18 polymorphic populations examined (Table 3 ) showing that there was no deficiency in heterozygotes from expected in many of the populations surveyed.

In contrast to the situation in $S$. squalidus, the most common allele at the $\beta E s t-3$ locus in $S$. vulgaris was the $\beta E s t-3 c$ allele (Table 6). This allele occurred at a frequency of 93 per cent in var. hibernicus, 82 per cent in var. vulgaris from populations polymorphic for capitulum type, and 83 per cent among individuals from populations monomorphic for var. vulgaris. At the $\alpha E s t-1$ locus, one allele $(\alpha E s t-1 a)$ was again present at very high frequency ( 92 per cent) in var. hibernicus, while in var. vulgaris from populations polymorphic and monomorphic for capitulum type, the allele occurred at 79 and 52 per cent, respectively. 
Table 3 Allele frequencies, observed heterozygosity $\left(H_{0}\right)$ and Wright's Fixation Index $\left(F_{0}\right)$ at the $\beta E s t-3$ locus in populations of Senecio squalidus

\begin{tabular}{|c|c|c|c|c|c|c|c|}
\hline Population & $\begin{array}{l}\text { National } \\
\text { grid reference }\end{array}$ & $\begin{array}{l}\text { Sample } \\
\text { size }\end{array}$ & $a$ & $b$ & $c$ & $H_{0}$ & $F_{0}$ \\
\hline \multicolumn{8}{|l|}{ England } \\
\hline Banbury & SP463404 & 50 & 0.01 & 0.95 & 0.04 & 0.060 & +0.375 \\
\hline Birmingham & SP092876 & 21 & 0.02 & 0.93 & 0.05 & 0.095 & +0.294 \\
\hline Chesterfield & SK383713 & 50 & 0.06 & 0.77 & 0.17 & 0.340 & +0.092 \\
\hline Darlington & NZ296146 & 15 & 0.13 & 0.84 & 0.03 & $0.067^{*}$ & +0.767 \\
\hline Dartford & TQ555743 & 25 & 0.04 & 0.96 & - & $0.000^{*}$ & +1.000 \\
\hline Derby & SK362356 & 44 & - & 1.00 & - & 0.000 & - \\
\hline Kingston & TQ191691 & 48 & - & 1.00 & - & 0.000 & - \\
\hline Oxford & SP505065 & 46 & 0.01 & 0.88 & 0.11 & $0.130^{*}$ & +0.387 \\
\hline Sheffield & SK395845 & 50 & - & 0.79 & 0.21 & $0.220^{*}$ & +0.337 \\
\hline St Helens & SJ524926 & 46 & - & 0.93 & 0.07 & 0.130 & -0.070 \\
\hline Stoke-on-Trent & SJ 886407 & 49 & - & 0.76 & 0.24 & 0.367 & +0.007 \\
\hline Warwick & SP286655 & 44 & - & 0.98 & 0.02 & 0.045 & -0.023 \\
\hline Wigan & SD594034 & 36 & - & 1.00 & - & 0.000 & - \\
\hline York & SE612518 & 26 & - & 1.00 & - & 0.000 & - \\
\hline \multicolumn{8}{|l|}{ Scotland } \\
\hline Edinburgh & NT268765 & 44 & 0.01 & 0.91 & 0.08 & 0.182 & -0.088 \\
\hline Glasgow & NS534671 & 34 & 0.07 & 0.93 & - & 0.147 & -0.079 \\
\hline Grangemouth & NS945825 & 35 & - & 0.89 & 0.11 & $0.000^{*}$ & +1.000 \\
\hline Methil & NT376995 & 26 & - & 0.96 & 0.04 & 0.077 & -0.040 \\
\hline \multicolumn{8}{|l|}{ Wales } \\
\hline Cardiff & ST173733 & 22 & - & 0.98 & 0.02 & 0.045 & -0.023 \\
\hline Mochdre & SH813774 & 26 & - & 0.90 & 0.10 & 0.192 & -0.106 \\
\hline Wrexham (Brymbo) & SJ296539 & 33 & - & 0.92 & 0.08 & 0.152 & -0.082 \\
\hline Wrexham (Rhostyllen) & SJ312492 & 27 & - & 1.00 & - & 0.000 & - \\
\hline Wrexham (Southsea) & SJ306515 & 25 & - & 0.98 & 0.02 & 0.040 & -0.020 \\
\hline Total & & 822 & 0.01 & 0.92 & 0.07 & 0.113 & 0.268 \\
\hline
\end{tabular}

*Observed genotypic frequencies significantly different from expected $(P<0.05)$ based on a test using exact probabilities.

The lower level of genetic diversity in var. hibernicus relative to var. vulgaris based on allelic frequencies was reflected in estimates of total gene diversity $\left(H_{T}\right)$ (Table 4). It was evident that over both esterase loci var. vulgaris contained approximately 3-3.5 times the amount of gene diversity present in var. hibernicus. For populations monomorphic for var. vulgaris, gene diversity stemmed mainly from allelic diversity between populations, i.e.

$G_{S T}=0.827$, where $G_{S T}=D_{S T / I T}$,

whereas for populations polymorphic for capitulum type, diversity resulted largely from variation within populations (var. vulgaris, $G_{S T}=0.292$; var. hibernicus $G_{S T}=0.337$ ). [Note that $G_{S T}$ is equivalent to $F_{S T}$ (Swofford \& Selander, 1981) as is evident from the values for these two statistics presented in Tables 4 and 5]. Low $G_{\mathrm{ST}}$ values are unexpected in colonizing and predominantly self-fertilizing species such as $S$. vulgaris. Much more common are high $G_{S T}$ values, i.e. of the type found for populations monomorphic for var. vulgaris (Hamrick \& Godt, 1990). In this regard, the accuracy of the low $G_{S T}\left(=F_{S T}\right)$ values calculated for both variants of $S$. vulgaris in polymorphic populations should be treated with some caution given the large sampling errors associated with these statistics when certain alleles occur at low frequency.

As expected for a predominantly selfing species, estimates of $F_{I T}$ were high in $S$. vulgaris, with the highest values exhibited by populations monomorphic for var. vulgaris (Table 5). These populations displayed a marked deficiency of heterozygotes from that expected with panmixia within populations (high $F_{I S}$ values) in addition to the considerable genetic subdivision between populations already mentioned (high $F_{S T}$ and $G_{S T}$ values). The high $F_{I T}$ values exhibited by var. vulgaris and var. hibernicus from populations polymorphic for capitulum type resulted largely from heterozygote deficiency within populations.

The genetic similarity between populations within 
Table 4 Estimates of gene diversity in S. squalidus, S. vulgaris var. vulgaris and var. hibernicus. $S$. vulgaris taxa from populations polymorphic and monomorphic for capitulum type are indicated by $(\mathrm{p})$ and $(\mathrm{m})$ respectively

\begin{tabular}{llllll}
\hline Taxon & Locus & $H_{T}$ & $H_{S}$ & $D_{S T}$ & $G_{S T}$ \\
\hline S. squalidus & $\beta E s t-3$ & 0.143 & 0.132 & 0.011 & 0.077 \\
S. vulgaris var. vulgaris $(\mathrm{p})$ & $\beta E s t-3$ & 0.292 & 0.194 & 0.098 & 0.336 \\
& $\alpha E s t-1$ & 0.313 & 0.235 & 0.078 & 0.249 \\
& Mean & 0.302 & 0.214 & 0.088 & 0.292 \\
S. vulgaris var. hibernicus $(\mathrm{p})$ & $\beta E s t-3$ & 0.112 & 0.070 & 0.042 & 0.375 \\
& $\alpha E s t-1$ & 0.103 & 0.074 & 0.029 & 0.284 \\
& Mean & 0.109 & 0.072 & 0.037 & 0.337 \\
S. vulgaris var. vulgaris $(\mathrm{m})$ & $\beta E s t-3$ & 0.287 & 0.050 & 0.237 & 0.826 \\
& $\alpha E s t-1$ & 0.486 & 0.084 & 0.402 & 0.827 \\
& Mean & 0.386 & 0.067 & 0.319 & 0.827 \\
\hline
\end{tabular}

Table $5 F$ statistics estimated for S. squalidus, S. vulgaris var. vulgaris and var. hibernicus. S. vulgaris taxa from populations polymorphic and monomorphic for capitulum type are indicated by $(\mathrm{p})$ and $(\mathrm{m})$ respectively

\begin{tabular}{lllll}
\hline Taxon & Locus & $F_{I T}$ & $F_{S T}$ & $F_{I S}$ \\
\hline S. squalidus & $\beta E s t-3$ & 0.302 & 0.078 & 0.243 \\
S. vulgaris var. vulgaris $(\mathrm{p})$ & $\beta E s t-3$ & 0.916 & 0.355 & 0.874 \\
& $\alpha E s t-1$ & 0.849 & 0.252 & 0.799 \\
& Mean & 0.882 & 0.292 & 0.833 \\
S. vulgaris var. hibernicus $(\mathrm{p})$ & $\beta E s t-3$ & 0.789 & 0.371 & 0.665 \\
& $\alpha E s t-1$ & 0.867 & 0.287 & 0.813 \\
S. vulgaris var. vulgaris $(\mathrm{m})$ & Mean & 0.826 & 0.331 & 0.740 \\
& $\beta E s t-3$ & 0.983 & 0.825 & 0.906 \\
& $\alpha E s t-1$ & 0.960 & 0.827 & 0.769 \\
& Mean & 0.969 & 0.826 & 0.820 \\
\hline
\end{tabular}

taxa, and also between taxa, was further quantified by computing Nei's genetic identity, I, (Nei, 1972) for each pair of populations taken in turn

$I=\frac{\sum x_{i} y_{i}}{\sqrt{\Sigma} x_{i}^{2} \Sigma y_{i}^{2}}$

where $x_{i}$ and $y_{i}$ are the frequencies of the $i$ th allele in populations $X$ and $Y$ respectively). This was conducted using BIOSYS-1, after which a mean genetic identity was calculated for each taxon or pair of taxa investigated (Table 7). Mean genetic identity averaged over both esterase loci was greater among populations of var. hibernicus than populations of var. vulgaris, with populations monomorphic for var. vulgaris exhibiting the lowest gene identity. Comparisons between taxa, revealed that the genetic identity between var. vulgaris and var. hibernicus, sampled from populations polymorphic for the two variants, was considerably greater than the identities computed between populations of these taxa and populations monomorphic for var. vulgaris.

Analysis at the $\beta E s t-3$ locus showed that genetic identities between $S$. vulgaris taxa and $S$. squalidus were very low, as expected given the level of divergence in allelic frequencies between these two species. Not surprisingly, a very high value for $I$ was computed for $S$. squalidus populations at the $\beta E s t-3$ locus emphasizing the lack of allelic diversity between populations in this species.

Estimates of gametic phase disequilibrium $(\hat{D})$ at the $\alpha E s t-1$ and $\beta E s t-3$ pair of loci were calculated for the few populations of $S$. vulgaris in which both loci were polymorphic (Table 8 ). Values of gametic phase disequilibrium $(\hat{D})$ were estimated from genotypic frequencies following the procedure of Weir et al. (1972) and tested for significance using the statistic

$Q=n \hat{D}^{2} /\left(p_{1} p_{2} q_{1} q_{2}\right)$ 
Table 6 Allele frequencies, observed heterozygosity $\left(H_{0}\right)$ and Wright's Fixation Index $\left(F_{0}\right)$ at the $\alpha E s t-1$ and $\beta E s t-3$ loci in Senecio vulgaris-var. vulgaris $(\mathrm{V})$ and var. hibernicus $(\mathrm{H})$

\begin{tabular}{|c|c|c|c|c|c|c|c|c|c|c|c|c|}
\hline \multirow[b]{2}{*}{ Population } & \multirow{2}{*}{$\begin{array}{l}\text { National } \\
\text { grid reference }\end{array}$} & \multirow[b]{2}{*}{ Variant } & \multirow{2}{*}{$\begin{array}{l}\text { Sample } \\
\text { size }\end{array}$} & \multicolumn{4}{|c|}{$\alpha E s t-1$} & \multicolumn{5}{|l|}{$\beta E s t-3$} \\
\hline & & & & $a$ & $b$ & $H_{0}$ & $F_{0}$ & $a$ & $b$ & $c$ & $H_{0}$ & $F_{0}$ \\
\hline \multicolumn{13}{|c|}{ Polymorphic for var. vulgaris and var. hibernicus } \\
\hline \multirow{2}{*}{$\begin{array}{l}\text { England } \\
\text { Birmingham }\end{array}$} & & $\mathrm{V}$ & 50 & 100 & - & 0.000 & & & & & & \\
\hline & SP092876 & $\mathrm{H}$ & 50 & 1.00 & $\overline{-}$ & $\begin{array}{l}0.000 \\
0.000\end{array}$ & $\overline{-}$ & 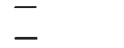 & $\begin{array}{l}0.02 \\
0.07\end{array}$ & $\begin{array}{l}0.98 \\
0.93\end{array}$ & $\begin{array}{l}0.000 \\
0.100\end{array}$ & $\begin{array}{l}1.000 \\
0.232\end{array}$ \\
\hline \multirow[t]{2}{*}{ St Helens } & SJ524926 & $\mathrm{V}$ & 40 & 1.00 & - & 0.000 & - & 0.05 & 0.49 & 0.46 & 0.275 & 0.496 \\
\hline & & $\mathrm{H}$ & 40 & 1.00 & - & 0.000 & - & - & - & 1.00 & 0.000 & - \\
\hline \multicolumn{13}{|l|}{ Scotland } \\
\hline \multirow[t]{2}{*}{ Edinburgh (i) } & NT261762 & $\mathrm{V}$ & 44 & 0.84 & 0.16 & 0.045 & 0.830 & - & 0.13 & 0.87 & 0.023 & 0.896 \\
\hline & & $\mathrm{H}$ & 40 & 0.95 & 0.05 & 0.000 & 1.000 & - & 0.05 & 0.95 & 0.000 & 1.000 \\
\hline \multirow[t]{2}{*}{ (ii) } & NT276763 & $\mathrm{V}$ & 43 & 0.33 & 0.67 & 0.279 & 0.365 & - & 0.45 & 0.55 & 0.023 & 0.953 \\
\hline & & $\mathrm{H}$ & 45 & 0.84 & 0.16 & 0.090 & 0.662 & - & 0.10 & 0.90 & 0.200 & -0.111 \\
\hline \multirow[t]{2}{*}{ (iii) } & NT268765 & $\mathrm{v}$ & 50 & 0.64 & 0.36 & 0.040 & 0.913 & - & 0.20 & 0.80 & 0.000 & 1.000 \\
\hline & & $\mathrm{H}$ & 70 & 0.48 & 0.52 & 0.060 & 0.857 & - & 0.02 & 0.98 & 0.070 & -0.022 \\
\hline \multirow[t]{2}{*}{ (iv) } & NT335708 & V & 17 & 0.79 & 0.21 & 0.294 & 0.101 & - & 0.29 & 0.71 & 0.000 & 1.000 \\
\hline & & $\mathrm{H}$ & 13 & 0.92 & 0.08 & 0.000 & 1.000 & - & - & 1.00 & 0.000 & - \\
\hline \multirow[t]{2}{*}{ (v) } & NT337725 & $\mathrm{V}$ & 50 & 0.98 & 0.02 & 0.000 & 1.000 & - & 0.46 & 0.54 & 0.120 & 0.758 \\
\hline & & $\mathrm{H}$ & 50 & 1.00 & - & 0.000 & - & - & 0.07 & 0.93 & 0.020 & 0.846 \\
\hline \multirow{2}{*}{ Glasgow (i) } & NS578664 & $\mathrm{V}$ & 25 & 1.00 & - & 0.000 & - & - & 0.28 & 0.72 & 0.000 & 1.000 \\
\hline & & $\mathrm{H}$ & 25 & 1.00 & - & 0.000 & - & - & - & 1.00 & 0.000 & - \\
\hline \multirow{2}{*}{ (ii) } & NS534671 & V & 25 & 1.00 & - & 0.000 & - & - & 0.04 & 0.96 & 0.000 & 1.000 \\
\hline & & $\mathrm{H}$ & 25 & 1.00 & - & 0.000 & - & - & - & 1.00 & 0.000 & - \\
\hline Grangemouth (i) & NS977814 & $\mathrm{V}$ & 25 & 0.84 & 0.16 & 0.000 & 1.000 & - & - & 1.00 & 0.000 & - \\
\hline & & $\mathrm{H}$ & 25 & 0.98 & 0.02 & 0.040 & -0.020 & - & - & 1.00 & 0.000 & - \\
\hline (ii) & NS913823 & V & 25 & 0.58 & 0.42 & 0.040 & 0.918 & - & - & 1.00 & 0.000 & - \\
\hline & & $\mathrm{H}$ & 25 & 0.96 & 0.04 & 0.000 & 1.000 & - & - & 1.00 & 0.000 & - \\
\hline Methil & NT376995 & $\mathrm{V}$ & 32 & 0.77 & 0.23 & 0.094 & 0.739 & - & 0.03 & 0.97 & 0.000 & 1.000 \\
\hline & & $\mathrm{H}$ & 36 & 1.00 & - & 0.000 & - & - & - & 1.00 & 0.000 & - \\
\hline Wales & & & & & & & & & & & & \\
\hline Cardiff & ST273733 & $\begin{array}{l}\mathrm{V} \\
\mathrm{H}\end{array}$ & $\begin{array}{l}33 \\
27\end{array}$ & $\begin{array}{l}0.94 \\
1.00\end{array}$ & 0.06 & $\begin{array}{l}0.000 \\
0.000\end{array}$ & -1.000 & - & $\begin{array}{l}0.73 \\
0.09\end{array}$ & 0.27 & $\begin{array}{l}0.000 \\
0.037\end{array}$ & $\begin{array}{l}1.000 \\
0.780\end{array}$ \\
\hline Mochdre & SH822781 & $\mathrm{V}$ & 45 & 0.62 & 0.38 & 0.000 & 1.000 & - & - & 1.00 & 0.000 & - \\
\hline & & $\mathrm{H}$ & 40 & 1.00 & - & 0.000 & - & - & 0.64 & 0.36 & 0.025 & 0.946 \\
\hline Wrexham (Brymbo) & SJ296539 & $\mathrm{V}$ & 38 & 0.70 & 0.30 & 0.026 & 0.938 & - & - & 1.00 & 0.000 & - \\
\hline & & $\mathrm{H}$ & 21 & 0.88 & 0.12 & 0.048 & $\begin{array}{r}0.773 \\
-\quad\end{array}$ & - & - & $\begin{array}{l}1.00 \\
1.00\end{array}$ & $\begin{array}{l}0.000 \\
0.000\end{array}$ & $\overline{-}$ \\
\hline Wrexham (Ffrith) & SJ286556 & $\begin{array}{l}\mathrm{V} \\
\mathrm{H}\end{array}$ & $\begin{array}{l}37 \\
16\end{array}$ & $\begin{array}{l}1.00 \\
1.00\end{array}$ & $\overline{-}$ & $\begin{array}{l}0.000 \\
0.000\end{array}$ & $\bar{z}$ & $\overline{-}$ & - & 1.00 & 0.000 & $\overline{-}$ \\
\hline Wrexham & & & & & & & & & & & & \\
\hline (Rhostyllen) & SJ312492 & $\begin{array}{l}\mathrm{V} \\
\mathrm{H}\end{array}$ & $\begin{array}{l}28 \\
14\end{array}$ & 0.97 & 0.03 & $\begin{array}{l}0.000 \\
0.000\end{array}$ & $-^{1.000}$ & $\overline{-}$ & - & $\begin{array}{l}1.00 \\
1.00\end{array}$ & $\begin{array}{l}0.000 \\
0.000\end{array}$ & $\overline{-}$ \\
\hline Wrexham & & $\mathrm{H}$ & 14 & & & & & & & & & \\
\hline (Southsea\} & SJ306515 & $\begin{array}{l}\mathrm{V} \\
\mathrm{H}\end{array}$ & $\begin{array}{l}65 \\
32\end{array}$ & $\begin{array}{l}0.51 \\
1.00\end{array}$ & $\begin{array}{l}0.49 \\
-\end{array}$ & $\begin{array}{l}0.031 \\
0.000\end{array}$ & $-^{0.938}$ & - & $\begin{array}{l}0.02 \\
0.03\end{array}$ & $\begin{array}{l}0.98 \\
0.97\end{array}$ & $\begin{array}{l}0.000 \\
0.000\end{array}$ & $\begin{array}{l}1.000 \\
1.000\end{array}$ \\
\hline Total & & $\mathrm{V}$ & 672 & 0.79 & 0.21 & 0.042 & 0.876 & $(0.003)$ & 0.18 & 0.82 & 0.028 & 0.904 \\
\hline & & $\mathrm{H}$ & 594 & 0.92 & 0.08 & 0.019 & 0.881 & - & 0.07 & 0.93 & 0.034 & 0.755 \\
\hline Monomorphic for var. vul & garis & & & & & & & & & & & \\
\hline $\begin{array}{l}\text { England } \\
\text { London }\end{array}$ & TQ349807 & $\mathrm{v}$ & 45 & 0.01 & 0.99 & 0.023 & -0.011 & - & - & 1.00 & 0.000 & - \\
\hline Scotland & & & & 0.95 & 0.05 & 0.033 & 0.649 & & 0.02 & 0.98 & 0.033 & -0.017 \\
\hline $\begin{array}{l}\text { Dundee } \\
\text { Methil }\end{array}$ & $\begin{array}{l}\text { NO373295 } \\
\text { NT377998 }\end{array}$ & $\mathrm{v}$ & 25 & - & 1.00 & 0.000 & - & - & - & 1.00 & 0.000 & - \\
\hline Wales & & & & & & & & & & & & \\
\hline Aberffraw & SH366656 & $\mathrm{V}$ & 25 & 0.94 & 0.06 & 0.040 & 0.645 & - & 1.00 & - & 0.000 & - \\
\hline Puffin Island & SH653824 & $\mathrm{v}$ & 25 & 0.98 & 0.02 & 0.039 & -0.020 & - & 0.20 & 0.80 & 0.000 & 1.000 \\
\hline $\begin{array}{l}\text { Spain } \\
\text { Matalascañas }\end{array}$ & & $\mathrm{V}$ & 20 & 0.20 & 0.80 & 0.000 & 1.000 & - & - & 1.00 & 0.000 & - \\
\hline $\begin{array}{l}\text { Switzerland } \\
\text { Basel }\end{array}$ & & & & & & 0000 & - & - & & & 000 & \\
\hline Total & & $\mathrm{v}$ & 15 & 1.00 & 0.48 & 0.022 & 0.957 & - & - & $\begin{array}{l}1.00 \\
0.83\end{array}$ & $\begin{array}{l}0.000 \\
0.005\end{array}$ & - \\
\hline
\end{tabular}

The sample from the Edinburgh (i) population was different from that subjected to a preliminary survey of esterase variation in $S$. vulgaris (see Materials and Methods), and did not contain the $\beta E s t-3 a$ allele found in the earlier sample. 
Table 7 Mean genetic identities, I, (Nei, 1972) within and between taxa. Standard errors are in brackets. Populations of $S$. vulgaris polymorphic and monomorphic for capitulum type are indicated by $(\mathrm{p})$ and $(\mathrm{m})$ respectively

\begin{tabular}{|c|c|c|c|c|}
\hline & \multicolumn{3}{|l|}{ Both esterase loci } & \multirow{3}{*}{$\begin{array}{l}\beta E s t-3 \text { locus } \\
\text { S. squalidus }\end{array}$} \\
\hline & \multicolumn{3}{|c|}{ S. vulgaris } & \\
\hline & var. vulgaris $(\mathrm{m})$ & var. vulgaris $(\mathrm{p})$ & var. hibernicus & \\
\hline \multicolumn{5}{|l|}{ S. vulgaris } \\
\hline var. vulgaris (m) & $0.640(0.306)$ & $0.675\{0.307\}$ & $0.671\{0.335)$ & $0.231(0.332)$ \\
\hline var. vulgaris $(\mathrm{p})$ & & $0.882(0.119)$ & $0.917(0.104)$ & $0.295(0.297)$ \\
\hline var. hibernicus $(\mathrm{p})$ & & & $0.958(0.080)$ & $0.097(0.095)$ \\
\hline S. squalidus & & & & $0.991(0.012)$ \\
\hline
\end{tabular}

Table 8 Gametic disequilibrium $(\hat{D})$ values for the $\alpha E s t-1$ and $\beta E s t-3$ pair of loci in populations of $S$. vulgaris var. vulgaris and var. hibernicus

\begin{tabular}{|c|c|c|c|c|}
\hline \multirow[b]{2}{*}{ Population } & \multicolumn{2}{|c|}{ Polymorphic for capitulum type } & \multicolumn{2}{|c|}{ Monomorphic for capitulum type } \\
\hline & var. vulgaris & var. hibernicus & Population & var. vulgaris \\
\hline \multicolumn{5}{|l|}{ Edinburgh } \\
\hline (i) & +0.0027 & $-0.0225^{*}$ & Dundee & +0.0008 \\
\hline (ii) & $+0.0619 \dagger$ & +0.0005 & & \\
\hline (iii) & +0.0120 & +0.0112 & & \\
\hline (iv) & +0.0311 & - & & \\
\hline (v) & -0.0108 & - & & \\
\hline Cardiff & $+0.0443^{*}$ & - & & \\
\hline Wrexham (Southsea) & -0.0001 & - & & \\
\hline Methil & $+0.0072 \dagger$ & - & & \\
\hline
\end{tabular}

${ }^{*} P<0.05 ; \dagger P<0.01$.

where $n$ is the number of individuals scored and $p_{1}, p_{2}$ and $q_{1}, q_{2}$ are the allele frequencies at the $\alpha E s t-1$ and $\beta E s t-3$ loci respectively. $Q$ is approximately distributed as $\chi^{2}$ with one degree of freedom (Hill, 1974). In populations polymorphic for capitulum type, significant gametic phase disequilibrium was present in var. vulgaris at one site, and in var. hibernicus at a second site. Furthermore, at two other sites, $\hat{D}$ was close to being significant $(P<10$ per cent $)$ in var. vulgaris. Clearly, there is evidence of non-random associations occurring in allelic state between the linked $\alpha E s t-1$ and $\beta E s t-3$ loci within var. vulgaris or var. hibernicus in at least some populations which are polymorphic for the two morphs. Furthermore, it is of interest that in such populations, one morph may exhibit significant gametic phase disequilibrium while the other does not.

\section{Discussion}

It is evident from the results of the present survey that the recently evolved radiate stabilized introgressant of
S. vulgaris, var. hibernicus, contains much less genetic diversity at two esterase encoding loci than the ancestral, non-radiate taxon $S$. vulgaris var. vulgaris. This was borne out from comparisons of allelic frequency, total gene diversity $\left(H_{T}\right)$, and genetic identity (I) within taxa, and was evident irrespective of whether var. vulgaris was sampled from populations containing both var. hibernicus and var. vulgaris, or populations monomorphic for var. vulgaris. With respect to total gene diversity, the values obtained for var. vulgaris were 3-3.5 times greater than that for var. hibernicus.

The lower level of genetic diversity in var. hibernicus relative to var. vulgaris, based on esterase variation, accords with the findings of a previous study which investigated variation in the two morphs for a range of life-history traits (Abbott, 1986). For most characters investigated, var. vulgaris exhibited more genetic diversity within populations than was present in var. hibernicus. In contrast, a survey of variation for aspartate aminotransferase (AAT) in $S$. vulgaris (Abbott et al., 1992) has shown that var. hibernicus contains more 
allelic diversity for Aat-3 than does var. vulgaris due to the introgression of the Aat-3c allele from $S$. squalidus.

A reduced level of genetic diversity in a recently evolved stabilized introgressant, relative to that in the species as a whole, is not unexpected given that only a small sample of the allelic diversity in the parental (recipient) species is likely to be incorporated in the introgressant. Only at loci where new alleles have been introgressed from the donor species is diversity likely to be increased. In the case of var. hibernicus, it is evident that the introgressant taxon has gained no increased genetic diversity for esterases from the donor species $S$. squalidus, despite the fact that $S$. squalidus possesses one esterase locus, $\beta E s t-1$, which is not present in $S$. vulgaris var. vulgaris, and also contains an allele at high frequency at the $\beta E s t-3$ locus which is at low frequency in var. vulgaris. Presumably the effects of either recurrent backcrossing, selection or random factors acting independently or in combination have prevented the $\beta E s t-1$ locus from being incorporated into var. hibernicus. Similarly, one or more of these factors may have acted to prevent the maintenance of the $\beta E s t-3 b$ allele in var. hibernicus at a frequency greater than in var. vulgaris, assuming, that is, that the $\beta E s t-3 b$ allele was present in the $S$. squalidus plant(s) which first crossed with $S$. vulgaris var. vulgaris at the initial stage of the introgression process.

Although a reduced level of allelic diversity at the $\alpha E s t-1$ and $\beta E s t-3$ loci in var. hibernicus relative to var. vulgaris may not be unexpected for comparisons involving populations monomorphic for var. vulgaris, it is surprising that this varietal difference is maintained in populations containing both variants. The outcrossing rate between the two variants in populations polymorphic for capitulum type is known to reach 35 per cent on occasion (Marshall \& Abbott, 1984) and it would be expected, therefore, for differences in allelic frequency between the variants to disappear quickly given that neither esterase locus is linked to the ray floret locus. The fact that differences in allelic frequency are maintained at esterase loci might indicate that a breeding barrier exists between the two variants of $S$. vulgaris which is not reflected by the intermorph outcrossing rate. This is further suggested by the results of an analysis of gametic disequilibrium $(\hat{D})$ in each morph. In two of the three populations where it was possible to compute $\hat{D}$ for each morph, it was established that when one morph exhibited significant gametic disequilibrium the other did not. A reduction in gene flow between the two variants would occur if the products of intermorph crossing were of reduced fitness relative to intramorph offspring. Some evidence in support of this hypothesis comes from the work of Marshall (1982) who found that in all populations of $S$. vulgaris, investigated, which contained both var. hibernicus and var. vulgaris, the observed fixation index at the ray floret locus was greater than expected based on the recorded outcrossing rates of morphs in these populations. One explanation for this would be that the products of intermorph crossing were of reduced fitness. Further study is required, however, to substantiate this hypothesis.

If some form of breeding barrier is present between var. hibernicus and var. vulgaris in populations containing both variants, this might act not only to maintain existing genetic differences between the variants but also to promote further divergence between the two variants in the future.

\section{Acknowledgements}

The work was supported by an NERC grant (Gr3) $6203 \mathrm{~A}$ ) to RJA. Part of the work was conducted while PAA was in receipt of an NERC postgraduate research studentship. We are grateful to David Forbes for technical assistance.

\section{References}

ABBoTT, R. J. 1986. Life history variation associated with the polymorphism for capitulum type and outcrossing rate in Senecio vulgaris L. Heredity, 56, 381-391.

ABBOTT, R. J., ASHTON, P. A. AND FORBES, D. G. 1992. Introgressive origin of the radiate groundsel, Senecio vulgaris L. var. hibernicus Syme: Aat-3 evidence. Heredity, 68, 425-435.

ALLARD, R. W. 1956. Formulas and tables to facilitate the calculation of recombination values in heredity. Hilgardia, 24, 235-278.

ANDERSON, E. 1949. Introgressive Hybridization. Wiley, N. Y. ANDERSON, E. 1953. Introgressive Hybridization. Biol. Rev. Cambridge Philos. Soc., 28, 280-307.

ASHTON, P. A. 1990. Multiple origins of Senecio cambrensis Rosser, and related evolutionary studies in British Senecio. Ph.D. thesis, University of St. Andrews.

ASHTON, P. A. AND ABBOTT, R. J. 1992. Multiple origins and genetic diversity in the newly arisen allopolyploid species, Senecio cambrensis Rosser (Compositae). Heredity, 68, 25-32.

DRUCE, G. C. 1927. The Flora of Oxfordshire. 2nd edn. Clarendon Press, Oxford.

GRANT, v. 1981. Plant Speciation. 2nd edn. Columbia University Press, N.Y.

HAMRICK, J. L. AND GODT, M. J. w. 1990. Allozyme diversity in plant species. In: Brown, A. H. D., Clegg, M. T., Kahler, A. L. and Weir, B. S. (eds) Plant Population Genetics, Breeding and Genetic Resources. Sinauer, MA., pp. 43-63. HILL, W. G. 1974. Estimation of linkage disequilibrium in randomly mating populations. Heredity, 33, 229-239.

HULL, P. 1974. Self-fertilization and the distribution of the radiate form of Senecio vulgaris $\mathrm{L}$. in Central Scotland. Watsonia, 10, 69-75. 
IRWIN, J. A. 1990. Male competition and outcrossing rate in a hermaphrodite plant. Ph.D. thesis, University of St. Andrews.

MANWELL, C. AND BAKER, C. M. A. 1970. Molecular Biology and the Origin of Species. Sidgewick \& Jackson, London.

MARSHALL, D. F. 1982. Studies on the breeding system of Senecio vulgaris $L$. Ph.D. thesis, University of St. Andrews.

MARSh ALL, D. F. AND ABBOTT, R. J. 1984. Polymorphism for outcrossing rate at the ray floret locus in Senecio vulgaris L. II. Confirmation. Heredity, 52, 331-336.

NEI, M. 1972. Genetic distance between populations. Am. Nat., 106, 283-292.

NEI, M. 1973. Analysis of gene diversity in subdivided populations. Proc. Nat. Acad. Sci., U.S.A., 70, 3321-3323.

RIESEBERG, L. H., BECKSTROM-STERNBERG, S. AND DOAN, K. 1990. Helianthus annuus ssp. texanus has chloroplast DNA and nuclear ribosomal RNA genes of Helianthus debilis ssp. cacumerifolius. Proc. Nat. Acad. Sci., U.S.A., 87, 593-597.
STEBBINS, G. 1969. The significance of hybridization for plant taxonomy and evolution. Taxon, 18, 26-35.

SUITER, K. A., WENDEL, J. F. AND CASE, J. S. 1983. LINKAGE-1: a PASCAL computer program for the detection and analysis of linkage. J. Hered., 74, 203-204.

SWOFFORD, D, L. AND SELANDER, R. B. 1981. Blosys-1, Release 1. A computer program for the analysis of allelic variation in Genetics. University of Illinois at Urbana-Champaign, Urbana.

TROW, A. H. 1912. On the inheritance of certain characters in the Common Groundsel, Senecio vulgaris L., and its segregates. J. Genet., 2, 239-276.

WEEDEN, N. F. AND WENDEL, J. F. 1989. Genetics of plant isozymes. In: Soltis, D. E. and Soltis, P. S. (eds) Isozymes in Plant Biology. Chapman and Hall, London, pp. 46-72.

WEIR, B. S., ALLARD, R. W. AND KAHLER, A. L. 1972. Analysis of complex allozyme polymorphisms in a barley population. Genetics, 72, 505-523.

WRIGHT, s. 1951. The genetical structure of populations. Ann. Eugen., 15, 323-354. 